\title{
Different isoforms of secreted aspartyl proteinases (Sap) are expressed by Candida albicans during oral and cutaneous candidosis in vivo
}

\author{
MARTIN SCHALLER, ELFRIEDE JANUSCHKE, CAROLIN SCHACKERT, BIRGIT WOERLE and \\ HANS C. KORTING
}

Department of Dermatology and Allergology, Ludwig-Maximilians-University Munich, Munich, Germany

\begin{abstract}
Distinct isoforms of secreted aspartyl proteinases (Sap) of Candida albicans are important virulence factors for different types of candidosis. Predominant expression of Sap1-3 has been shown to be crucial for superficial infections in experimental mucosal and cutaneous candidosis, whereas Sap4-6 might be important for systemic disease. This in-vivo study investigated Sap expression in two samples from patients with oral candidosis and from cutaneous infection. Two different polyclonal antibodies directed against Sap1-3 and Sap4-6 were used for ultrastructural characterisation of protein localisation and expression. Post-embedding immuno-electron microscopy revealed Sap1-3 and Sap4-6 immunoreactivity in all samples. All $C$. albicans cells expressed predominantly the proteinases Sap1-3 which were evenly distributed within the cell wall and cytoplasmic membrane. In contrast, Sap4-6 labelling was only evident in a few fungal cells. In particular it was localised at the tips of hyphal cells during invasion. These data suggest a different pathogenetic role for Sap1-3 and Sap4-6 during host-fungal interaction.
\end{abstract}

\section{Introduction}

Superficial infections by Candida albicans are common diseases in immunocompromised patients. Among the putative virulence factors of $C$. albicans, secretion of hydrolytic enzymes such as aspartyl proteinases seems to be an important determinant for pathogenicity $[1,2]$. Ten members of a gene family encoding different secreted aspartyl proteinases (Sap1-10) have been isolated to date [3-5]. In-vitro and in-vivo studies have demonstrated that these genes are differentially regulated (A. Felk, W. Schäfer, B. Hube, unpublished data) $[3,5,6-13]$. Present evidence suggests that the success of the fungal pathogen in different types of infections depends partly on the expression of distinct virulence factors such as members of the $S A P$ gene family [12-22]. Whereas $S A P 4-6$ has been shown to facilitate systemic infections, expression of $S A P 1-3$ appears critical for the virulence of $C$. albicans in superficial candidosis. These results were obtained by studying the virulence phenotype of $C$. albicans mutants defective in distinct $S A P$ genes in comparison

Received 29 Sept. 2000; revised version accepted 20 Feb. 2001.

Corresponding author: $\operatorname{Dr}$ M. Schaller (e-mail: Martin. Schaller@1rz.uni-muenchen.de). to the parental strain during infection. Models for testing were mainly experimental animal infections [12, 14-19] or in-vitro test systems representing specific types of candida infections or distinct stages of the infection process [20-22]. Previous investigations used models of oral and cutaneous candidosis based on reconstituted human epithelium and epidermis (RHE) for virulence studies [9-11]. At the ultrastructural level, different patterns of Sap localisation have been demonstrated in these models by immuno-electron microscopy with polyclonal antibodies directed against Sap1-3 and Sap4-6 [23]. To date, the ultrastructural localisation of Sap immunoreactivity in vivo has been investigated only in experimental rat vaginitis [24] and oral candidosis in HIV-infected patients [25]. The antibodies used in both studies recognised only the gene products of $S A P 1-3$ as they were generated by immunisation with Sap2 [24] or with Sap1-3 [25].

In the present investigation, two different polyclonal antibodies specifically directed against Sap1-3 and Sap4-6 were used. Immuno-electron microscopy was used to examine different ultrastructural expression patterns for Sap1-3 and Sap4-6 during both oral and cutaneous candidosis in vivo, possibly reflecting distinct roles of these proteinases during the invasion process. 


\section{Materials and methods}

\section{Clinical parameters of patients}

Samples of pseudomembrane were removed by scraping from the buccal oral mucosa (male, female), from the left groin (male) and from the fold under the left breast (female) of four volunteer HIV-negative patients. The patients were 44, 58, 64 and 76 years old, untreated and all had been suffering from pseudomembranous candidosis for at least 2 weeks. Parts of the clinical material from all four patients were used for microbiological culture, biochemical characterisation and immuno-electron microscopy.

\section{Mycological examination}

The specimens were inoculated on Kimmig's Agar (Merck, Darmstadt, Germany) and incubated for $72 \mathrm{~h}$ at $37^{\circ} \mathrm{C}$. Biochemical identification of C. albicans was based on the ATB 32 C system (API System, bioMérieux, La Balme-les-Grottes, Montalieu Vercieu, France).

\section{Immuno-electron microscopy}

Post-embedding immunogold labelling was done as described previously [10]. After fixation, specimens were embedded in LR-White. Sections, 80-100 nm thick, were mounted on nickel grids. Grids were then incubated with anti-Sap polyclonal rabbit antibodies directed against Sap1-3 ( $\alpha$-Sap2) or against Sap4-6 $(\alpha$-Sap6F) [22]. After washing overnight with PBS, grids were incubated with $10 \mathrm{~nm}$ gold-conjugated goat anti-rabbit IgG (Auroprobe EM Immunogold reagents, Amersham, UK). Grids were then fixed with glutaraldehyde $2 \%$ and stained with uranyl acetate $0.5 \%$ for $10 \mathrm{~min}$ and lead citrate $2.7 \%$ for $5 \mathrm{~min}$ (Ultrastainer, LKB, Sweden) at $20^{\circ} \mathrm{C}$. A Zeiss EM 902 transmission electron microscope (Zeiss, Oberkochen, Germany) operating at $80 \mathrm{kV}$ was used for examination, at magnifications between $3000 \times$ and $85000 \times$.

\section{Results}

C. albicans was identified in all four patients. There were no obvious differences apparent in the localisation and distribution of Sap1-3 and Sap4-6 immunoreactivities between samples from oral and cutaneous candidosis. To avoid repetition, the different stages of interaction between $C$. albicans and host cells (without contact, adhesion, invasion, within keratinocytes following invasion) are not demonstrated in detail for both mucosal and cutaneous candidosis. Labelling with the Sap1-3 antibody showed a regularly distributed intensive immunoreactivity in all $C$. albicans cells of the mucosal (Fig. 1A-C) and the cutaneous samples (Fig. 1D). Sap1-3 immunoreactivity was mainly localised adjacent to the cell wall and the cytoplasmic membrane of all C. albicans cells (Fig. 1A-D). No significant difference in the density and distribution of Sap1-3 expression was observed between yeast (Fig. 1A, B, D) or hyphal cells (Fig. 1C). The pattern of enzyme labelling of $C$. albicans not in direct contact with the keratinocytes (Fig. 1A) was similar to that of fungal cells at the adhesion stage (Fig. 1B), invading (Fig. 1C) or within keratinocytes following cell invasion (Fig. 1D).

In contrast, labelling with the antibody directed against Sap4-6 revealed gold particles only in a few $C$. albicans cells of the mucosal (Fig. 2A, B, D) and cutaneous samples (Fig. 2C). In particular, enzyme labelling was found at the tips of those hyphal elements which penetrated host tissue (Fig. 2C). Where $C$. albicans was not in direct contact with (Fig. 2A), or adhering to host cells (Fig. 2B) or inside keratinocytes following cell invasion (Fig. 2D) there were very few or no gold particles after labelling with the Sap4-6 antibody. No specific gold labelling was seen in control experiments without the addition of the polyclonal antibodies Sap1-3 or Sap4-6.

\section{Discussion}

Immuno-electron microscopy studies with two polyclonal antibodies specifically directed against Sap1-3 and Sap4-6 demonstrated different ultrastructural patterns of enzyme expression for Saps during oral and cutaneous candidosis in vivo. Sap1-3 was expressed by all fungal cells and may be relevant for the infection process in general. Sap4-6 seems to have a particular function during direct interaction with the host, especially during hyphal invasion or penetration. Earlier studies used reconstituted human epithelium or epidermis for establishing in-vitro models of oral or cutaneous candidosis [9-11]. At the ultrastructural level, labelling with antibodies demonstrated a similar expression pattern for Sap1-3 and Sap4-6 during experimental oral and cutaneous infections [9-11]. The patterns of Sap secretion in the present study correspond to the results of the in-vitro models and confirm the usefulness of these infection systems for mimicking the situation in vivo. To date, in-vivo investigations of Sap secretion have been performed only in a rat vaginitis model and during oral candidosis of HIV-infected patients [23, 24]. Both studies clearly demonstrated protein secretion by $C$. albicans, but labelling was directed only against Sap1-3 and, therefore, failed to recognise Sap4-6 immunoreactivity. The results of the present study imply that the majority of Saps important for pathogenicity during oral or cutaneous infections with $C$. albicans are Sap1-3 and not Sap4-6. In contrast, a high production of Sap4-6 by $C$. albicans cells was detected during interaction with murine peritoneal macrophages [22]. These results imply a direct role of Sap1-3 for tissue damage during superficial infections, while Sap4-6 seems to be more 

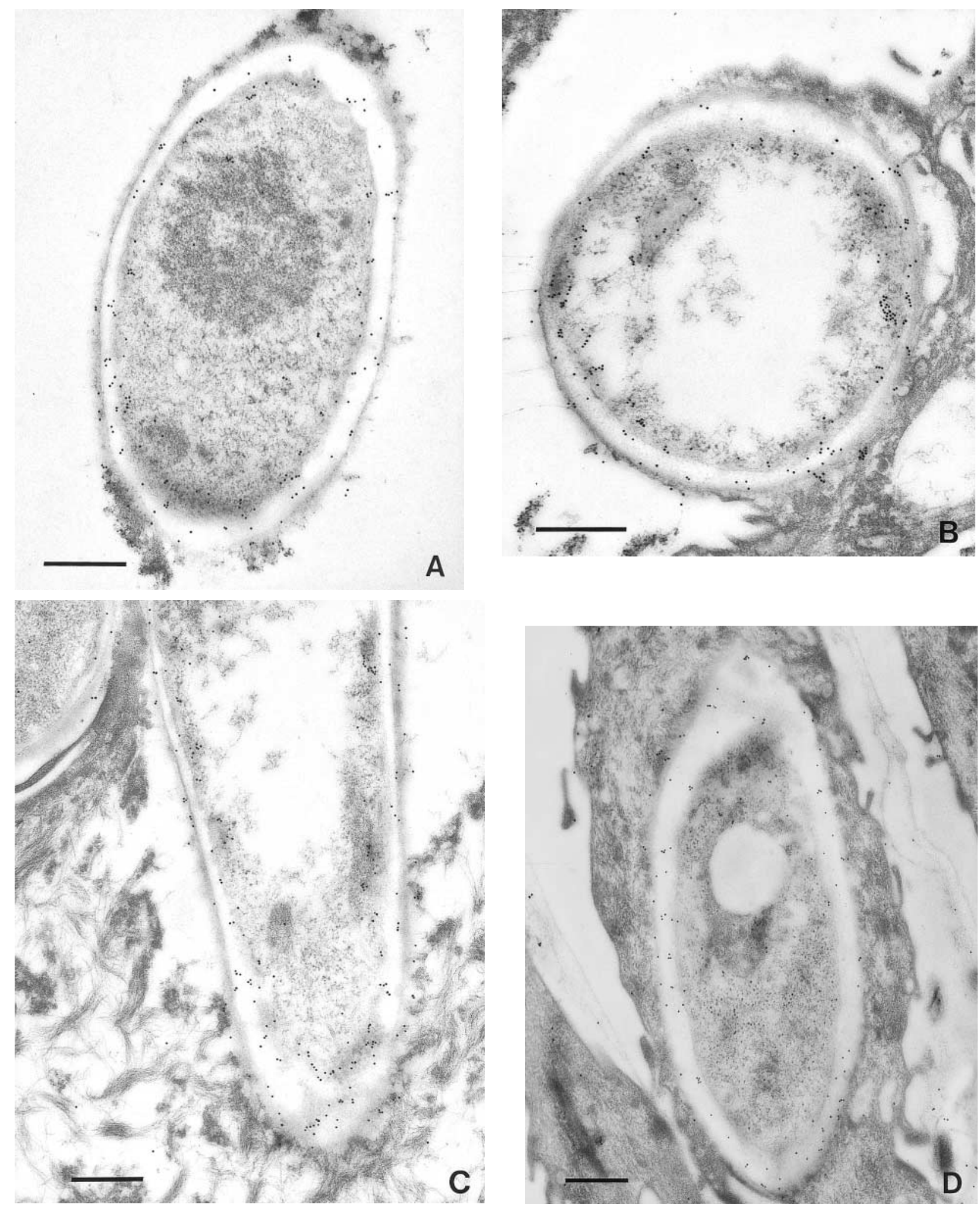

Fig. 1. Electron micrograph with post-embedding immunogold labelling against Sap1-3, with 10-nm gold particles in samples of $C$. albicans from oral and cutaneous candidosis showing regular distribution of Sap1-3 antigen within the cell wall of all C. albicans cells. (A) Fungal cell not in direct contact with host cells; (B) adherent C. albicans cell; (C) invasion of a keratinocyte by C. albicans; (D) C. albicans within a keratinocyte following cell invasion. Bars $=0.5 \mu \mathrm{m}$.

important for penetration into deeper tissues and interactions with the cellular defence.

The relevance of $S A P 1-3$ for mucosal and cutaneous candidosis has also been illustrated by gene expression studies [6,9-11] and infection experiments with $S A P$ null mutants $[10,11,14,15,21]$. The importance of SAP1-3 for infection in vivo is supported by analysis of 

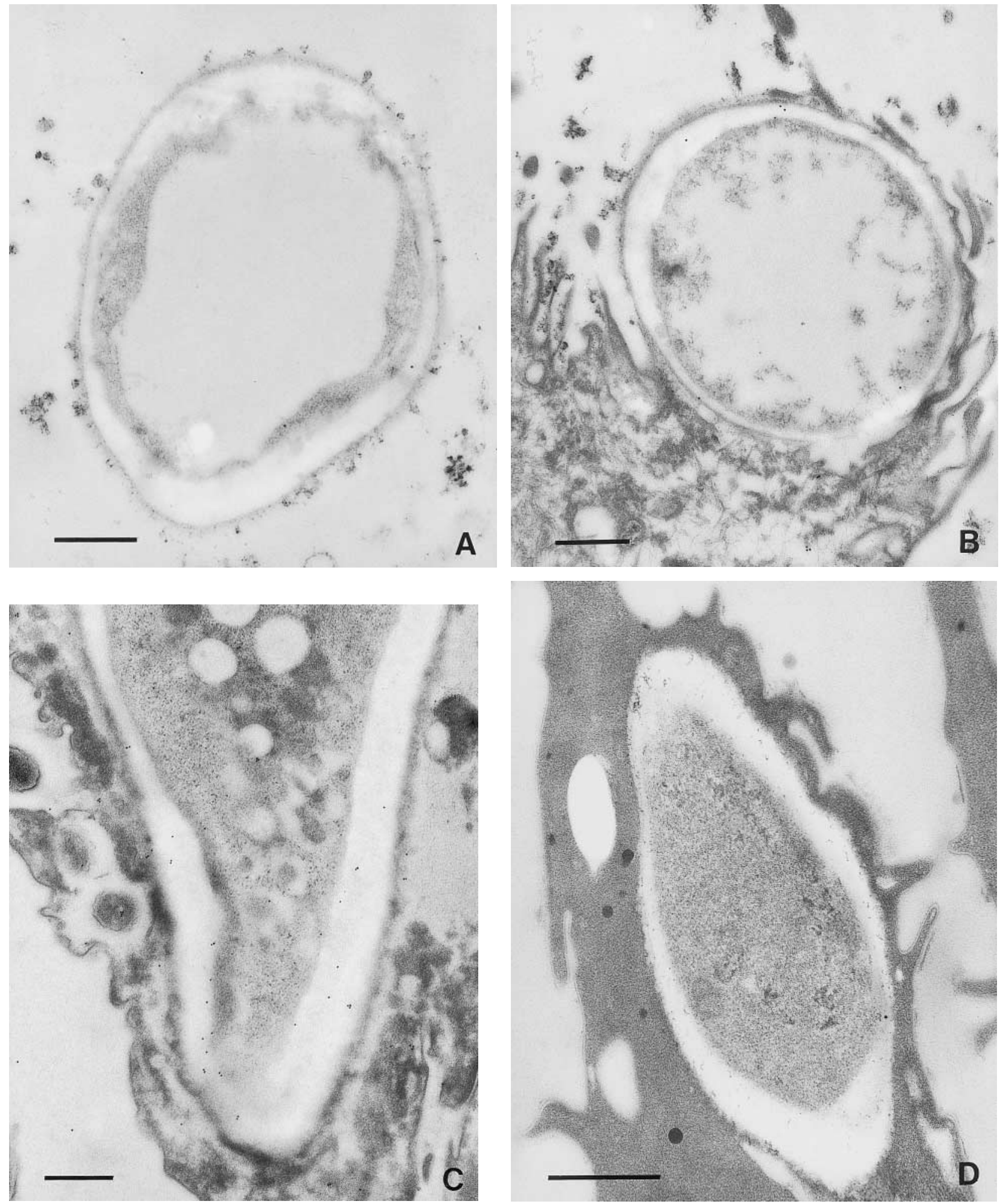

Fig. 2. Electron micrograph with post-embedding immunogold labelling against Sap4-6, with 10-nm gold particles in samples of $C$. albicans from oral and cutaneous candidosis. The great majority of $C$. albicans cells remain unlabelled. Very few if any gold particles are observed (A) in fungal cells not in contact with host cells, (B) at the adhesion stage and $(\mathbf{C})$ in $C$. albicans within the keratinocytes following cell invasion. (D) Significant labelling can be only detected at the tips of a few invading hyphal cells. Bars $=0.5 \mu \mathrm{m}$.

SAP expression in human oral candidosis. Transcripts for $S A P 1$ and $S A P 3$ were found only in patients with clinical manifest infections but not in asymptomatic carriers [9, 25]. At the protein level expression of Sap of $C$. albicans was recently demonstrated in human saliva [26].
In summary, these results suggest differing roles for Sap1-3 and Sap4-6 in pathogenicity during oral and cutaneous candidosis in vivo.

We thank B. Hube (University of Hamburg, Hamburg, Germany) and W. Burgdorf (Ludwig-Maximilians-University, Munich, Germany) for 
critical reading of the manuscript and M. Monod (Centre Hôpitalier Universitaire Vaudois, Lausanne, Switzerland) for providing the polyclonal antibodies. This article contains parts of the doctoral thesis written by C.S. at the medical faculty of the Ludwig-MaximiliansUniversity Munich. M.S. was supported by a grant from the Münchner Medizinischen Wochenschrift e.V.

\section{References}

1. Cutler JE. Putative virulence factors of Candida albicans. Annu Rev Microbiol 1991; 45: 187-218.

2. Odds FC. Candida species and virulence. ASM News 1994; 60: $313-318$.

3. Hube B. Candida albicans secreted aspartyl proteinases. Curr Top Med Mycol 1996; 7: 55-69.

4. Monod M, Togni G, Hube B, Sanglard D. Multiplicity of genes encoding secreted aspartic proteinases in Candida species. Mol Microbiol 1994; 13: 357-368.

5. Monod M, Hube B, Heß D, Sanglard D. Differential regulation of $S A P 8$ and $S A P 9$, which encode two new members of the secreted aspartic proteinase family in Candida albicans. Microbiology 1998; 144: 2731-2737.

6. De Bernardis F, Cassone A, Sturtevant J, Calderone R. Expression of Candida albicans SAP1 and SAP2 in experimental vaginitis. Infect Immun 1995; 63: 1887-1892.

7. Hube B, Monod M, Schofield DA, Brown AJP, Gow NAR. Expression of seven members of the gene family encoding secretory aspartyl proteinases in Candida albicans. Mol Microbiol 1994; 14: 87-99.

8. Morrow B, Srikantha T, Soll DR. Transcription of the gene for a pepsinogen, $P E P 1$, is regulated by white-opaque switching in Candida albicans. Mol Cell Biol 1992; 12: 2997-3005.

9. Schaller M, Schäfer W, Korting HC, Hube B. Differential expression of secreted aspartyl proteinases in a model of human oral candidosis and in patient samples from the oral cavity. Mol Microbiol 1998; 29: 605-615.

10. Schaller M, Korting HC, Schäfer W, Bastert J, Chen W, Hube B. Secreted aspartic proteinase (Sap) activity contributes to tissue damage in a model of human oral candidosis. Mol Microbiol 1999; 34: 169-180.

11. Schaller M, Schackert C, Korting HC, Januschke E, Hube B. Invasion of Candida albicans correlates with expression of secreted aspartic proteinases (Sap) during experimental infection of human epidermis. J Invest Dermatol 2000; 114: $712-717$.

12. Staib P, Kretschmar M, Nichterlein $\mathrm{T}$ et al. Host-induced, stage-specific virulence gene activation in Candida albicans during infection. Mol Microbiol 1999; 32: 533-546.

13. White TC, Agabian N. Candida albicans secreted aspartyl proteinases: isoenzyme pattern is determined by cell type, and levels are determined by environmental factors. J Bacteriol
1995; 177: 5215-5221.

14. De Bernardis F, Arancia S, Morelli L et al. Evidence that members of the secretory aspartyl proteinase gene family, in particular SAP2, are virulence factor for Candida vaginitis. $J$ Infect Dis 1999; 179: 201-208.

15. Dubois N, Colina AR, Aumont F, Belhumeur P, de Repentigny L. Overexpression of Candida albicans secretory aspartyl proteinase 2 and its expression in Saccharomyces cerevisiae do not augment virulence in mice. Microbiology 1998; 144: 2299-2310.

16. Hube B, Sanglard D, Odds FC et al. Disruption of each of the secreted aspartyl proteinase genes $S A P 1, S A P 2$, and $S A P 3$ in Candida albicans attenuates virulence. Infect Immun 1997; 65: 3529-3538.

17. Kretschmar M, Hube B, Bertsch $\mathrm{T}$ et al. Germ tubes and proteinase activity contribute to virulence of Candida albicans in murine peritonitis. Infect Immun 1999; 67: 6637-6642.

18. Sanglard D, Hube B, Monod M, Odds FC, Gow NAR. A triple deletion of the SAP4, SAP5 and SAP6 of Candida albicans causes attenuated virulence. Infect Immun 1997; 65: 3539-3546.

19. Kvaal C, Lachke SA, Srikantha T, Daniels K, McCoy J, Soll DR. Misexpression of the opaque-phase-specific gene PEPI $(S A P 1)$ in the white phase of Candida albicans confers increased virulence in a mouse model of cutaneous infection. Infect Immun 1999; 67: 6652-6662.

20. Ibrahim AS, Filler SG, Sanglard D, Edwards JE, Hube B. Secreted aspartyl proteinases and interactions of Candida albicans with human endothelial cells. Infect Immun 1998; 66: 3003-3005.

21. Watts HJ, Cheah FSH, Hube B, Sanglard D, Gow NAR. Altered adherence in strains of Candida albicans harbouring null mutations in secreted aspartic proteinase genes. FEMS Microbiology Lett 1998; 159: 129-135.

22. Borg-von Zepelin M, Beggah S, Boggian K, Sanglard D, Monod M. The expression of the secreted aspartyl proteinases Sap4 to Sap6 from Candida albicans in murine macrophages. Mol Microbiol 1998; 28: 543-554.

23. Schaller M, Hube B, Ollert MW et al. In vivo expression and localization of Candida albicans secreted aspartyl proteinases during oral candidiasis in HIV-infected patients. $J$ Invest Dermatol 1999; 112: 383-386.

24. Stringaro A, Crateri P, Pellegrini G, Arancia G, Cassone A, De Bernardis F. Ultrastructural localization of the secretory aspartyl proteinase in Candida albicans cell wall in vitro and in experimentally infected rat vagina. Mycopathologia 1997; 137: $95-105$.

25. Naglik JR, Newport G, White TC et al. In vivo analysis of secreted aspartyl proteinase expression in human oral candidiasis. Infect Immun 1999; 67: 2482-2490.

26. Wu T, Samaranayake LP. The expression of secreted aspartyl proteinases of Candida species in human whole saliva. J Med Microbiol 1999; 48: 711-720. 